\title{
RANKING OF DEVELOPED SOFTWARE USING FUZZY COMPOSITE PROGRAMMING
}

\author{
DR.(Mrs.) Nisha Agrawal ${ }^{1}$
}

\begin{abstract}
A model using the Fuzzy Composite Programming is developed to select the most appropriate software and then aggregate and weight of normalize basic criteria into more general groups. Several factors considered to the selection decision are used in the ranking and evaluating the proposed alternatives. Sensitivity analysis is discussed that will enable to perform high level quality analysis of the given software systems. The model developed in this paper is simple to use and allows to consider all decision relevant factors.
\end{abstract}

Keywords: Decision making, uncertainty, fuzzy numbers, multi-level, multi-objective, fuzzy composite programming, normalization, sensitivity analysis.

\section{INTRODUCTION}

Decision making for the best alternative, while considering various criteria that influence, is difficult and this difficulty is further complicated not only when conflicting relationships exist between the criteria considered, but also when qualitative criteria are included in considering the criterion. The uncertainties and the qualitative human thoughts, which are difficult to measure in quantitative value for the criteria, can be represented as fuzzy numbers, and these fuzzy numbers can then be normalized to compose the criteria directly under a hierarchical structure. In addition, the final result may vary with the value of importance assigned to each of criteria, which can also vary according to the opinion of different decision makers.

The challenges in using the proposed decision framework would be defining and specifying the types of fuzzy numbers for linguistic variables and establishing the scale of preference structure to be used by Decision Makers. When there are many stakeholders with different interests in the outcomes of the project, it would be more difficult and complicated to establish the preference of scale structure as each of them may have different ideas about the importance of the decision criteria. Further it becomes more complicated and fuzzier to evaluate making group decisions. In many practical situations the problem of ranking various alternatives under conditions of risk and uncertainty is encountered where both tangible and intangible parameters are to be considered. Therefore, there exists a need of a model for solving the

${ }^{1}$ Department of Applied Mathematics and Computational Sc. Shri G.S.Institute of Technology \& Science,Indore,Madhya Pradesh,India 
problem of Choosing the best alternative (or best courses of action) or making a complete ranking of a finite set of alternatives. The problem involves decision making[1] under condition of risk and uncertainty.

In this paper, a multi-level, multi-objective, decision making methodology using fuzzy composite programming is developed where there are conflicting objectives, the objectives have different preferences (weights), and the value of each input variable is uncertain. A model is also developed for sensitivity analysis to understand the effects of a slight modification of user's preferences on the ranking of various alternatives. The model has been implemented on MS-Excel.

\section{METHODOLOGY}

In order to make a decision among the different alternatives, it is necessary to consider the various criteria, which influence alternatives. In this paper, fuzzy set theory and hierarchical structure analysis are used. Fuzzy sets[5], which was introduced by Zadeh [18], are used to describe the inherent imprecision and ambiguity associated with the criterion for the alternative. The use of fuzzy sets will allow the user to include the unavoidable imprecision, which stems from the lack of available information or randomness of a future situation, and to quantify the qualitative criteria, which is difficult to evaluate as exact value. A systematic approach was developed to evaluate and choose the best alternative in the following five sequential steps:

$>$ Step 1: Selection of basic criteria, which influence to the alternatives.

$>$ Step 2: Normalization of selected basic criteria to compare directly.

$>$ Step 3: Aggregation and weighting of normalized basic criteria into more general groups by Fuzzy Composite Programming [2],[3].

$>$ Step 4: Evaluate and Rank the proposed alternatives.

$>$ Step 5: Sensitivity Analysis.

A. SELECTION OF BASIC CRITERIA: A number of criteria, which relate to the objectives, can be considered. These basic criteria are used as the input variables to evaluate each alternative. Since these basic criteria contain elements of uncertainty, these are estimated as fuzzy numbers to help characterize their uncertainty, which is inherent to a given set with a degree of membership as shown in Fig. 1. Let $Z_{i}(x)$ be a fuzzy number for the $i^{\text {th }}$ basic criterion and its membership function $\mu\left[Z_{i}(x)\right]$ be a trapezoid (or triangle), where $x$ denotes an element of the discrete set of the alternative being analyzed. The membership function for each of the basic criterion can be constructed as shown in Fig. 1, where $Z_{i, h}(x)$ is an interval value of the $i^{\text {th }}$ basic criteria at the confidence level $h$.

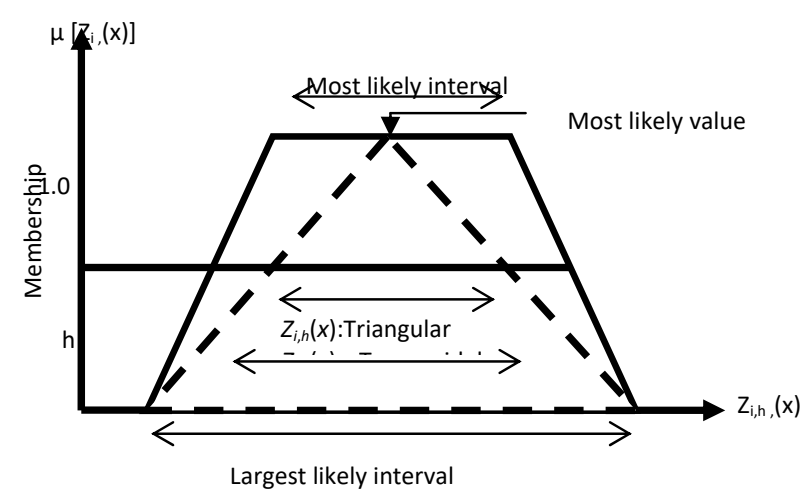

Fig. 1: Trapezoidal (triangular) membership function of fuzzy number. 
B. NORMALIZATION OF BASIC CRITERIA: The values of the basic criteria for the evaluation process are estimated as fuzzy values to characterize their uncertainty. The fuzzy values are numbers that belong to a given set (interval) with a degree of membership. Since the units of the basic criteria are different, thus making it difficult to compare them directly, the actual value of each basic criterion $\left[Z_{i, h}(x)\right]$ should be transformed into an index value [3]. The normalization process is performed by using the best and worst values for each basic criterion. The value of the $i^{\text {th }}$ fuzzy criterion is transformed into an $i^{\text {th }}$ normalized fuzzy index value with the help of predetermined best value $\left(B E S Z_{i}\right)$ and worst value $\left(W O R Z_{i}\right)$ for the $i^{\text {th }}$ basic criterion among the given alternatives. The best and worst values may be crisp or fuzzy in nature [8]. The actual value $Z_{i, h}(x)$ can be transformed into an index value $S_{i, h}(x)$ as shown in figure 2 .

(a) If $B E S Z_{i}>W O R Z_{i}$, then the $i^{\text {th }}$ normalized fuzzy criterion $\left[\mathrm{S}_{i, h}(x)\right]$ can be calculated by following equations:

$S_{i, h}(x)=\left\{\begin{array}{cl}1, & Z_{i, h}(x) \geq \text { BESZ }_{i} \\ \frac{Z_{i, h}(x)-\text { WORZ }_{i}}{B E S Z_{i}-W_{\text {WRZ }}}, & \text { WORZ }_{i}<Z_{i, h}(x)<\text { BESZ }_{i} \\ 0, & Z_{i, h}(x) \leq \text { WORZ }_{i}\end{array}\right.$

(b) $\mathrm{BESZ}_{i}<W O R Z_{i}$, then

$$
S_{i, h}(x)=\left\{\begin{array}{cl}
1, & Z_{i, h}(x) \leq \mathrm{BESZ}_{i} \\
\frac{Z_{i, h}(x)-\text { WORZ }_{i}}{\mathrm{BESZ}_{i}-\mathrm{WORZ}_{i}}, & \mathrm{BESZ}_{i}<Z_{i, h}(x)<\text { WORZ }_{i} \\
0, & Z_{i, h}(x) \geq \text { WORZ }_{i}
\end{array}\right.
$$

(a) $B E S Z_{i}>W O R Z_{i}$

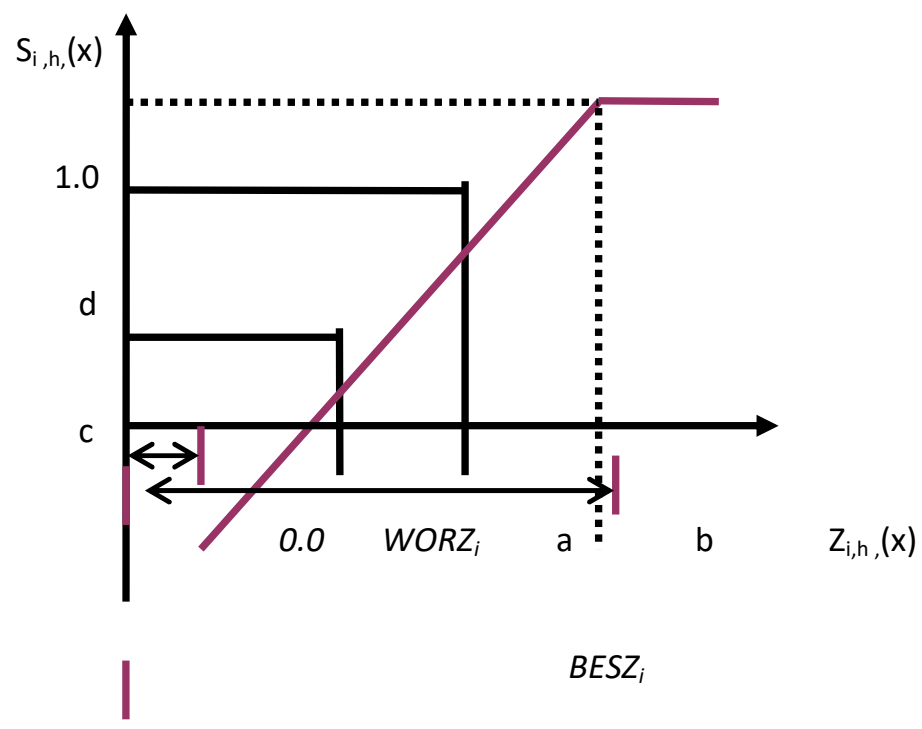

(b) $B E S Z_{i}<W O R Z_{i}$

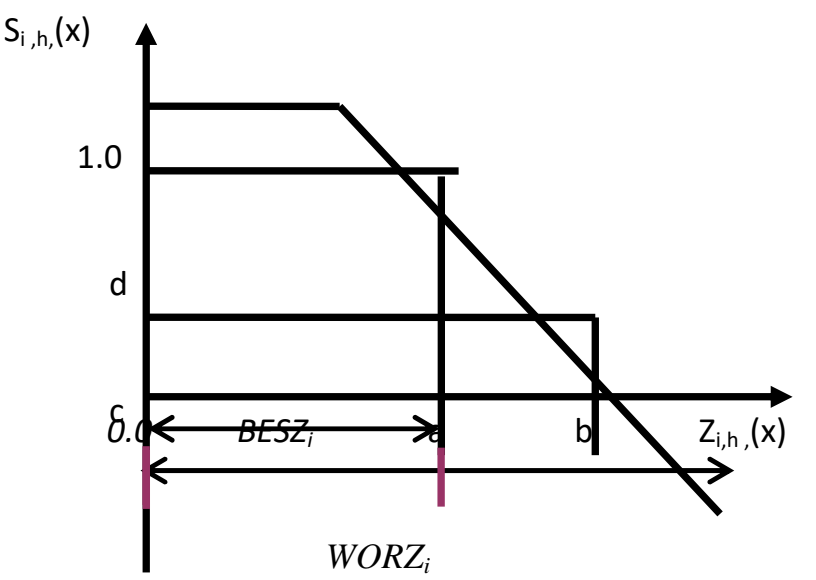

Fig. 2: Normalizing Actual Value $Z_{i, h}(x)$ into Index Value $S_{i, h}(x)$ 
C. FUZZY COMPOSITE PROCEDURE: The Composite(Aggregating) Procedure[4] involves a stepby-step regrouping of a set of basic criteria to form a single criterion. The interrelationships among the basic criteria can be expressed by the use of a hierarchical structure[13][14] as shown below in Fig. 3.

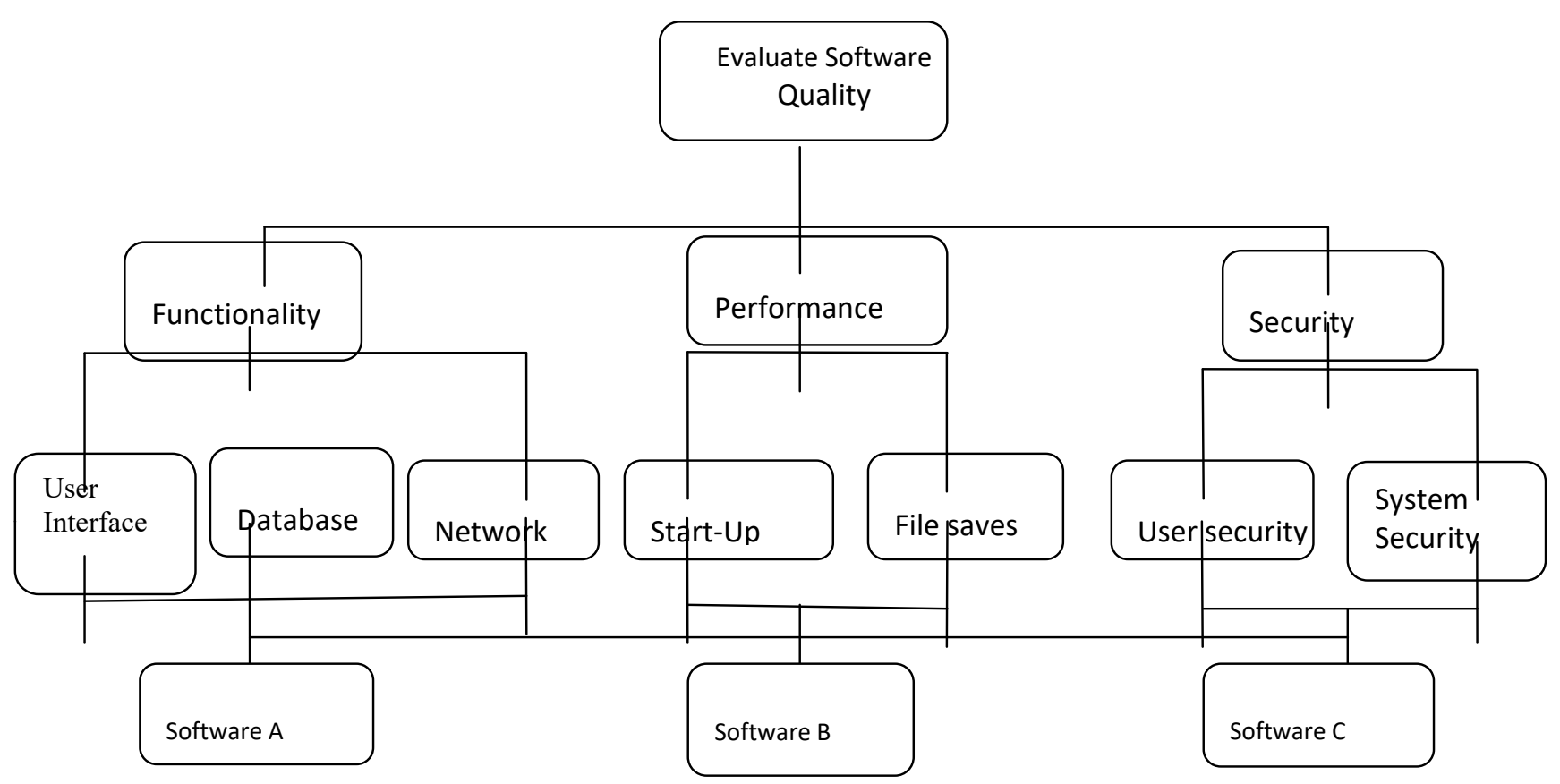

Figure 3: Hierarchy design for the software selection Model.

In this type of hierarchical structure, the elements of level 1 are constituted of the selected basic criteria. The criteria in the upper level can be obtained by aggregating the criteria in the lower level. The aggregating procedure continues until the final level fuzzy criterion (A Single Decision Index) is achieved.

Since decisions are based on the testing of all of the weighted descriptions for each alternative, the criterion must be integrated in some manner in order to make a decision. Aggregation is the process by which the fuzzy sets[6][7][8] that represent the output of each criterion influencing each alternative is integrated into a single fuzzy set. Aggregation is done only once for each output variable, just prior to the final step.

Accordingly Index values, $\mathrm{L}_{i, h}(x)$, for second level composite criteria can be calculated by using the index values of basic criteria, or

$$
L_{j, h}(x)=\left\{\sum_{i=1}^{n_{j}} W_{i j}\left[S_{i, h, j}(x)\right]\right\}
$$

where $\mathrm{n}_{\mathrm{j}}=$ the number of elements in the second-level group $j ; \mathrm{S}_{i, h, j}(x)=$ normalized $i^{\text {th }}$ fuzzy criterion in the second-level group $\mathrm{j}$ of basic criteria; and $\mathrm{W}_{i, j}=$ the weight reflecting the importance of each of basic criteria in group $j\left(\Sigma \mathrm{W}_{i, j}=1\right), Z_{i, h}(x)=$ value of the $i^{\text {th }}$ fuzzy criterion. $B E S Z_{i}$ and $W O R Z_{i}$ denote the best and worst values of the $i^{\text {th }}$ criterion, respectively. Similarly the index values at higher levels can be calculated. 
The final composite index value $\mathrm{L}_{\mathrm{n}}(\mathrm{x})$ can be obtained by combining the index values of the two last level criteria:

$$
\mathrm{L}_{n}(x)=\left\{\mathrm{w}_{1}\left[\mathrm{~L}_{1, \mathrm{~h}}(\mathrm{x})\right]+\mathrm{w}_{2}\left[\mathrm{~L}_{2, \mathrm{~h}}(\mathrm{x})\right]+\mathrm{w}_{3}\left[\mathrm{~L}_{3, \mathrm{~h}}(\mathrm{x})\right]+\ldots \ldots . .\right\}
$$

\section{Level 1}

Level 2

Level 3

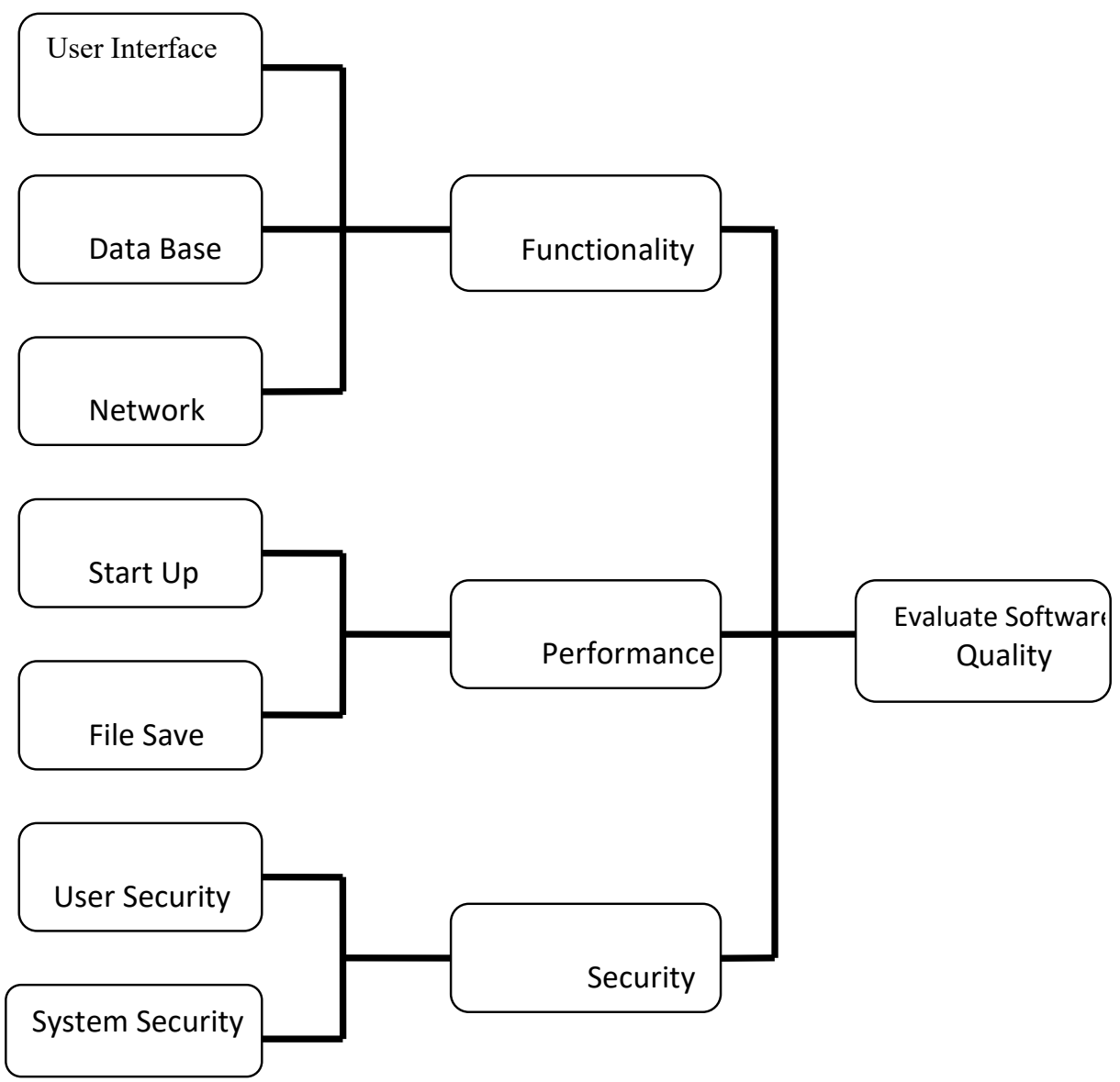

Figure 4: Fuzzy Composite Procedure.

Where $\mathrm{L}_{1, h}(x)=$ the index value for the first criterion in the final group , $\mathrm{L}_{2, h}(x)$ the index value for the second criterion in the final group and $\mathrm{L}_{3, h}(x)$ the index value for the third criterion in the final group and $\mathrm{w}_{1}, \mathrm{w}_{2}$ and $\mathrm{w}_{3}$ are the weights representing the relative importance between the three criteria in the final group.

D.EVALUATION AND RANKING OF ALTERNATIVES: Alternative However this index is a fuzzy number and a 'de-fuzzified' or expected value of the fuzzy number for each alternative is to be obtained to render the fuzzy number to be compared and ranked. For de-fuzzification, using the method of average mean criterion as given below in equation (5), the order value (index value) corresponding to a fuzzy number can be obtained.

DESCRIPTION OF ALTERNATIVES AND INPUT VALUES: The three alternatives have been chosen as Software A, Software B and Software C Here the basic criteria are first chosen and then they are grouped to obtain a system criterion by the method of composite programming. The seven basic 
criteria are shown in Figure 4 are chosen. These basic criteria are used as input variables to evaluate the alternatives The basic criteria are estimated as fuzzy numbers to help characterize them uncertainty. The method can be used to estimate the fuzzy numbers by consulting the experts and then consolidating the experts, inputs to model the inherent uncertainty of each criterion as a fuzzy number. The assumed fuzzy numbers (Basic Criteria Values) as can be obtained by taking experts opinion are tabulated in Table1 as input values.

TABLE 1. Basic Criteria Values for Alternatives

\begin{tabular}{|c|c|c|c|c|c|c|c|c|c|c|c|c|c|c|}
\hline \multicolumn{15}{|c|}{ Basic Criteria Values (Trapezoidal Fuzzy Numbers ) For Three Alternatives } \\
\hline \multirow[t]{2}{*}{ Basic Criteri: } & \multicolumn{4}{|c|}{ Alternative 1} & \multicolumn{4}{|c|}{ Alternative 2} & \multicolumn{4}{|c|}{ Alternative 3 } & \multirow{2}{*}{$\begin{array}{l}\text { Best } \\
\text { Valu }\end{array}$} & \multirow{2}{*}{$\begin{array}{l}\text { Worst } \\
\text { Value }\end{array}$} \\
\hline & \multicolumn{2}{|c|}{$\begin{array}{l}\text { Least like } \\
\text { interval }\end{array}$} & \multicolumn{2}{|c|}{$\begin{array}{l}\text { Most like } \\
\text { interval }\end{array}$} & \multicolumn{2}{|c|}{$\begin{array}{l}\text { Least } \\
\text { likely } \\
\text { interval }\end{array}$} & \multicolumn{2}{|c|}{$\begin{array}{l}\text { Most like } \\
\text { interval }\end{array}$} & \multicolumn{2}{|c|}{$\begin{array}{l}\text { Least } \\
\text { likely } \\
\text { interval }\end{array}$} & \multicolumn{2}{|c|}{$\begin{array}{l}\text { Most } \\
\text { likely } \\
\text { interval }\end{array}$} & & \\
\hline Start Up & 625 & 680 & 640 & 660 & 200 & 230 & 205 & 220 & 110 & 150 & 120 & 140 & 680 & 110 \\
\hline File Save & 200 & 240 & 210 & 230 & 410 & 470 & 420 & 460 & 300 & 360 & 320 & 350 & 470 & 200 \\
\hline User interfac & 260 & 310 & 270 & 300 & 130 & 160 & 135 & 150 & 550 & 600 & 565 & 585 & 600 & 130 \\
\hline Database & 150 & 185 & 160 & 175 & 310 & 360 & 32 & 350 & 480 & 520 & 490 & 510 & 520 & 150 \\
\hline Netv & 200 & 240 & 210 & 230 & 410 & 470 & 420 & 460 & 300 & 360 & 320 & 350 & 470 & 200 \\
\hline User security & 625 & 680 & 640 & 660 & 200 & 230 & 205 & 220 & 110 & 150 & 120 & 140 & 680 & 110 \\
\hline $\begin{array}{l}\text { System } \\
\text { Security }\end{array}$ & 260 & 310 & 270 & 300 & 130 & 160 & 135 & 150 & 550 & 600 & 565 & 585 & 600 & 130 \\
\hline
\end{tabular}

\section{CALCULATION OF NORMALIZED VALUES:}

First level Normalized Values: The Normalized Values are obtained for all the seven criteria using equations (1) and (2) and the calculated values are shown in Table 2.

Second level Normalized Values: The Normalized Values $L_{\mathrm{i}, \mathrm{h}}$ for second level composite criteria are obtained by using the equation (3), where the weights[15] for various criteria are taken from the following assumed matrix. Suppose

Matrix for functionality Matrix for performance Matrix for security

$$
\left(\begin{array}{ccc}
1 & 4 & 3 \\
0.27 & 1 & 2 \\
0.2 & 0.8 & 1 \\
1.43 & 3.8 & 8
\end{array}\right) \quad\left(\begin{array}{ll}
1 & 3 \\
8.2 & 1 \\
1.2 & 0
\end{array}\right) \quad\left(\begin{array}{cc}
1 & 8 \\
0.88 & 1 \\
1.83 & 4
\end{array}\right)
$$

TABLE 2. Normalised Value for basic criteria

\begin{tabular}{|c|c|c|c|c|c|c|c|c|c|c|c|c|}
\hline \multirow{2}{*}{ ITEM } & \multicolumn{4}{|c|}{ Alternative 1} & \multicolumn{4}{|c|}{ Alternative 2} & \multicolumn{4}{|c|}{ Alternative 3} \\
\hline & $\begin{array}{l}\text { Leas } \\
\text { inter }\end{array}$ & like & $\begin{array}{l}\text { Most } \\
\text { inter }\end{array}$ & like & & $\begin{array}{l}\text { st like } \\
\text { rval }\end{array}$ & $\begin{array}{l}\text { Most } \\
\text { inter }\end{array}$ & like & $\begin{array}{l}\text { Leas } \\
\text { inter }\end{array}$ & like & $\begin{array}{l}\text { Most } \\
\text { inter }\end{array}$ & $\begin{array}{l}\text { like } \\
\text { al }\end{array}$ \\
\hline $\begin{array}{l}\text { Software } \\
\text { Quality }\end{array}$ & 0.36 & 0.45 & 0.38 & 0.43 & 0.19 & 0.28 & 0.20 & 0.25 & 0.62 & 0.73 & 0.66 & 0.71 \\
\hline
\end{tabular}


TABLE 3. Normalization Values of Second Level Criteria I

\begin{tabular}{|c|c|c|c|c|c|c|c|c|c|c|c|c|c|}
\hline \multirow{3}{*}{$\begin{array}{l}\text { Second } \\
\text { Levlel } \\
\text { Criteria }\end{array}$} & \multicolumn{4}{|c|}{ Alternative 1} & \multicolumn{4}{|c|}{ Alternative 2} & \multicolumn{4}{|c|}{ Alternative 3} & \multirow{3}{*}{$\begin{array}{l}\text { Weight } \\
0.716\end{array}$} \\
\hline & \multicolumn{2}{|c|}{$\begin{array}{l}\text { Least } \\
\text { likely interva }\end{array}$} & \multicolumn{2}{|c|}{$\begin{array}{l}\text { Most } \\
\text { likely interval }\end{array}$} & \multicolumn{2}{|c|}{$\begin{array}{l}\text { Least } \\
\text { likely interval }\end{array}$} & \multicolumn{2}{|c|}{$\begin{array}{l}\text { Most } \\
\text { likely interval }\end{array}$} & \multicolumn{2}{|c|}{$\begin{array}{l}\text { Least } \\
\text { likely interval }\end{array}$} & \multicolumn{2}{|c|}{$\begin{array}{l}\text { Most } \\
\text { likely interva }\end{array}$} & \\
\hline & 0.753 & 0.858 & 0.781 & 0.822 & 0.261 & 0.343 & 0.275 & 0.322 & 0.062 & 0.157 & 0.089 & 0.137 & \\
\hline $\begin{array}{l}\text { Functiona } \\
\mathbf{y}\end{array}$ & 0.188 & 0.297 & 0.212 & 0.273 & 0.179 & 0.275 & 0.196 & 0.251 & 0.831 & 0.951 & 0.867 & 0.919 & 0.706 \\
\hline Security & 0.747 & 0.846 & 0.772 & 0.815 & 0.119 & 0.174 & 0.128 & 0.156 & 0.223 & 0.302 & 0.244 & 0.287 & 0.118 \\
\hline
\end{tabular}

TABLE 4. COMPOSITE FUZZY VALUES FOR THREE ALTERNATIVES

\begin{tabular}{|c|c|c|c|c|c|c|c|c|c|c|c|c|}
\hline \multicolumn{13}{|c|}{ Normalised Value for Basic Criteria } \\
\hline \multirow[b]{2}{*}{$\begin{array}{l}\text { Basic } \\
\text { Criteria }\end{array}$} & \multicolumn{4}{|c|}{ Alternative 1 } & \multicolumn{4}{|c|}{ Alternative 2} & \multicolumn{4}{|c|}{ Alternative 3} \\
\hline & \multicolumn{2}{|c|}{$\begin{array}{ll}\text { Least like } \\
\text { interval }\end{array}$} & \multicolumn{2}{|c|}{$\begin{array}{ll}\text { Most } & \text { like } \\
\text { interval } & \end{array}$} & \multicolumn{2}{|c|}{$\begin{array}{l}\text { Least like } \\
\text { interval }\end{array}$} & \multicolumn{2}{|c|}{$\begin{array}{l}\text { Most like } \\
\text { interval }\end{array}$} & \multicolumn{2}{|c|}{$\begin{array}{l}\text { Least like } \\
\text { interval }\end{array}$} & \multicolumn{2}{|c|}{\begin{tabular}{|l|}
$\begin{array}{l}\text { Most lik } \\
\text { interval }\end{array}$ \\
\end{tabular}} \\
\hline Start Up & 0.904 & 1 & 0.93 & 0.965 & 0.158 & 0.211 & 0.167 & 0.193 & 0 & 0.07 & 0.018 & 0.053 \\
\hline File Save & 0 & 0.148 & 0.037 & 0.111 & 0.778 & 1 & 0.815 & 0.963 & 0.37 & 0.593 & 0.444 & 0.556 \\
\hline $\begin{array}{l}\text { User } \\
\text { interface }\end{array}$ & 0.277 & 0.383 & 0.298 & 0.362 & 0 & 0.064 & 0.011 & 0.043 & 0.894 & 1 & 0.926 & 0.968 \\
\hline Database & 0 & 0.095 & 0.027 & 0.068 & 0.42 & 0.58 & 0.459 & 0.541 & 0.892 & 1 & 0.919 & 0.973 \\
\hline Network & 0 & 0.148 & 0.037 & 0.111 & 0.778 & 1 & 0.815 & 0.963 & 0.37 & 0.593 & 0.444 & 0.556 \\
\hline $\begin{array}{l}\text { User } \\
\text { security }\end{array}$ & 0.904 & 1 & 0.93 & 0.365 & 0.158 & 0.211 & 0.167 & 0.193 & 0 & 0.07 & 0.018 & 0.053 \\
\hline $\begin{array}{l}\text { System } \\
\text { Security }\end{array}$ & 0.277 & 0.383 & 0.298 & 0.362 & 0 & 0.064 & 0.011 & 0.043 & 0.894 & 1 & 0.926 & 0.968 \\
\hline \multicolumn{13}{|c|}{ Normalised Value for Basic Criteria } \\
\hline \multirow{2}{*}{$\begin{array}{l}\text { Basic } \\
\text { Criteria }\end{array}$} & \multicolumn{4}{|c|}{ Alternative 1} & \multicolumn{4}{|c|}{ Alternative 2} & \multicolumn{4}{|c|}{ Alternative 3} \\
\hline & \multicolumn{2}{|c|}{$\begin{array}{ll}\text { Least } & \text { like } \\
\text { interval }\end{array}$} & \multicolumn{2}{|c|}{$\begin{array}{l}\text { Most } \\
\text { interval }\end{array}$} & \multicolumn{2}{|c|}{\begin{tabular}{|l|}
$\begin{array}{l}\text { Least } \\
\text { interval }\end{array}$ \\
\end{tabular}} & \multicolumn{2}{|c|}{$\begin{array}{l}\text { Most } \\
\text { interval }\end{array}$} & \multicolumn{2}{|c|}{$\begin{array}{ll}\text { Least } \\
\text { interval like }\end{array}$} & \multicolumn{2}{|c|}{\begin{tabular}{|l|} 
Most \\
interval \\
\end{tabular}} \\
\hline Start Up & 0.904 & 1 & 0.93 & 0.965 & 0.158 & 0.211 & 0.167 & 0.193 & 0 & 0.07 & 0.018 & 0.053 \\
\hline File Save & 0 & 0.148 & 0.037 & 0.111 & 0.778 & 1 & 0.815 & 0.963 & 0.37 & 0.593 & 0.444 & 0.556 \\
\hline $\begin{array}{l}\text { User } \\
\text { interface }\end{array}$ & 0.277 & 0.383 & 0.298 & 0.362 & 0 & 0.064 & 0.011 & 0.043 & 0.894 & 1 & 0.926 & 0.968 \\
\hline Database & 0 & 0.095 & 0.027 & 0.068 & 0.42 & 0.58 & 0.459 & 0.541 & 0.892 & 1 & 0.919 & 0.973 \\
\hline Network & 0 & 0.148 & 0.037 & 0.111 & 0.778 & 1 & 0.815 & 0.963 & 0.37 & 0.593 & 0.444 & 0.556 \\
\hline $\begin{array}{l}\text { User } \\
\text { security }\end{array}$ & 0.904 & 1 & 0.93 & 0.365 & 0.158 & 0.211 & 0.167 & 0.193 & 0 & 0.07 & 0.018 & 0.053 \\
\hline $\begin{array}{l}\text { System } \\
\text { Security }\end{array}$ & 0.277 & 0.383 & 0.298 & 0.362 & 0 & 0.064 & 0.011 & 0.043 & 0.894 & 1 & 0.926 & 0.968 \\
\hline
\end{tabular}


- The second level normalized values are given in Table 3.

- The composite fuzzy value can be obtained by using equation (4), where weights $w_{1}, w_{2}$ and $w_{3}$ have been taken from the following matrix and normalized values from Table2.

$$
\text { Matrix for software quality }\left(\begin{array}{ccc}
1 & 4 & 0 \\
0,23 & 1 & 1,3 \\
0,17 & 0,67 & 1 \\
1,42 & 8,67 & 1
\end{array}\right)
$$

E. RANKING FUZZY NUMBERS \& SENSITIVITY ANALYSIS: If all the grades are real numbers, a total grades which is on a linear scale can be obtained when the grades are represented by fuzzy sets, the overall grade which is also a fuzzy set can be obtained. one is then faced with another ranking problem in which the grade is unique but fuzzy with uncertainty[19]. In the statistical decision analysis problem also, there are several decision making criteria to rank the alternatives. And in that all the criteria for ordering random variables are designed to define a function to convert the probability distribution to a single value (index) by which the decision could be made based on the largest index value. The same idea can be carried over to the ordering problem of fuzzy variables. There are many criteria to define the index function with different emphases and no single criterion is satisfactory for all situations. The choice of criteria is context dependent.

\section{THE FOUR POINT AVERAGE CRITERION:}

$$
\mu_{X}(x)
$$

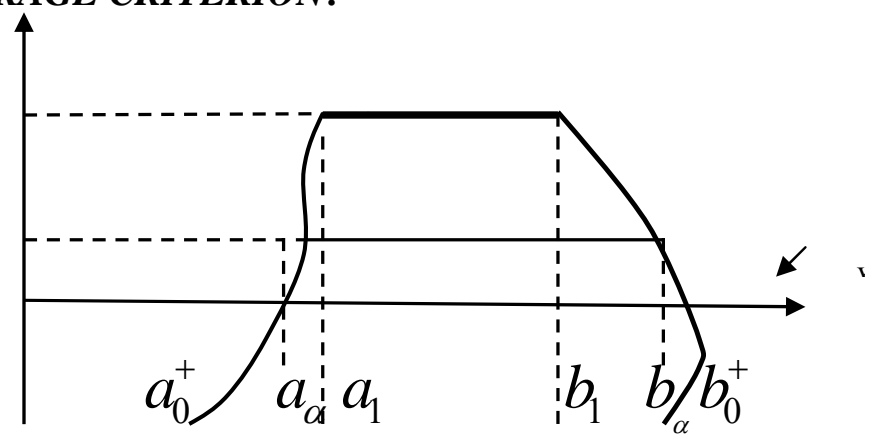

Figure 5: Fuzzy set representation for linguistic grades

For any computed grade of a specific alternative, we use four end points of two intervals: most possible interval and least possible interval. The average numerical grade is given by.

$$
\mathrm{G}=1 / 4\left(\mathrm{a}_{1}+\mathrm{b}_{1}+\mathrm{a}_{0}{ }^{+}+\mathrm{b}_{0}{ }^{+}\right) \quad \text {, Where } \mathrm{a}_{1}, \mathrm{~b}_{1}, \mathrm{a}_{0}{ }^{+}, \mathrm{b}_{0}{ }^{+} \text {are shown in Fig. }
$$

Since $\mathrm{G}$ is a real number, its order is well defined, in next section.

RANKING THE ALTERNATIVES: The ranking of alternatives can be done only after defuzzifying the composite fuzzy number for each alternative. Here the ranking of alternatives is made by using the four point average criterion. The average numerical grade is given by

$$
\mathrm{G}=1 / 4 \text { [ Sum of Most Likely Intervals }+ \text { Sum of Least Likely Intervals ] }
$$

Hence, the order value of the first alternative 


$$
=1 / 4[0.35+0.38+0.43+0.46]=0.41
$$

And the order value of the second alternative

$$
=1 / 4[0.19+0.20+0.25+0.28]=0.23
$$

And the order value of the third alternative

$$
=1 / 4[0.62+0.66+0.71+0.73]=0.68
$$

Since, the order value of the third alternative is greater than the order value of the other two alternatives, therefore third alternative is preferred to the first and second alternatives.

SENSITIVITY ANALYSIS: The decision makers may be interested to know how the ranking[16][17] (index values) of various alternatives will vary by changing the weights (relative importance) assigned to criteria at various levels. The variation can be plotted to provide a graphical view to the decision maker for taking appropriate decision, as shown below by the following graphs.

\begin{tabular}{|c|c|c|c|c|c|c|c|c|}
\hline \multicolumn{9}{|c|}{ WEIGHT FOR SECURITY=0.1 } \\
\hline FUNCTIONALITY & 0.1 & 0.2 & 0.3 & 0.4 & 0.5 & 0.6 & 0.7 & 0.8 \\
\hline PERFORMANCE & 0.8 & 0.7 & 0.6 & 0.5 & 0.4 & 0.3 & 0.2 & 0.1 \\
\hline SOFTWARE A & 0.666934297 & 0.610849077 & 0.554763857 & 0.498678636 & 0.44253416 & 0.386508196 & 0.33042298 & 0.27433776 \\
\hline SOFTWARE B & 0.262580297 & 0.255102042 & 0.247623787 & 0.240145532 & 0.23667276 & 0.225189021 & 0.21771077 & 0.21023251 \\
\hline SOFTWARE C & 0.178132652 & 0.256201708 & 0.334270763 & 0.412339819 & 0.49408874 & 0.56847783 & 0.64654699 & 0.72461604 \\
\hline
\end{tabular}

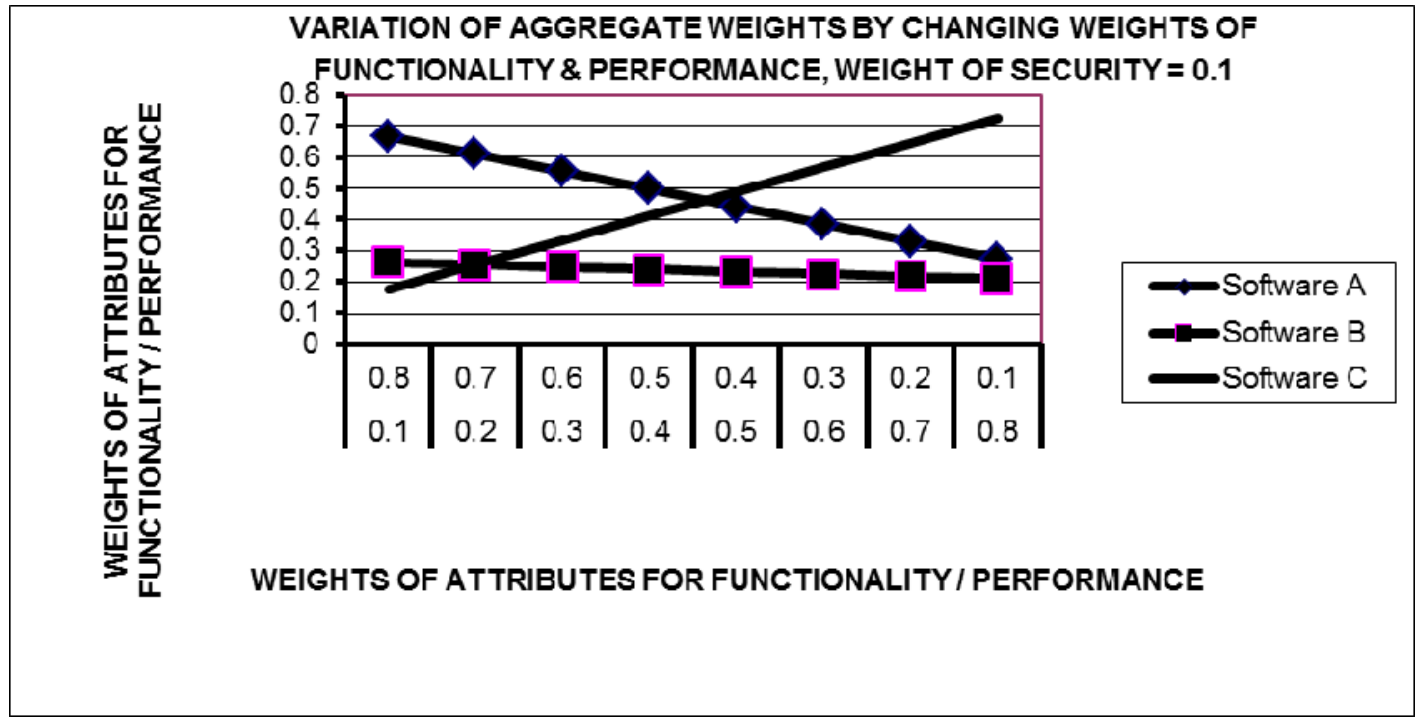




\section{CONCLUSION}

The Fuzzy set Theory[9][10] which deals with a set of objects characterized by a membership function that assigns to each object a grade of membership ranging between zero and one is introduced and attempt is made to model uncertainty by using fuzzy numbers.

The methodology of extracting fuzzy numbers from experts is presented . The concepts that must be considered when modelling uncertainty using fuzzy arithmetic[11][12] are introduced. Various approaches for representing uncertainty are discussed. A brief discussion of evaluation of multi attributes based on multi-attributes decision theory is made. The interval analysis and fuzzy set theory are introduced to represent and process vague and imprecise information. The risk assessment expert system is descried and its application illustrated with an example.

Finally, for ranking alternatives, fuzzy composite programming method has been described to provide useful tool to solve decision making problems where there are conflicting objectives, the objective have varying degrees of importance, and value of input variables are uncertain. A multi-level, multi-objective programming method using fuzzy sets to represent the uncertainty in input variables has been developed.

The model has been implemented using Microsoft Excel, for evaluating and ranking various alternatives, based on both, the analytic Hierarchy process and Fuzzy Composite Programming methods. A simple procedure is developed to get the sensitivity Analysis of the problem to study the variation, because of change in the values of input parameters. The identification of situations in which a slight modification of user preferences might lead to the selection of a different alternatives is vital, since user input is not always absolute and final.

\section{REFERENCES}

[1] Anurag Garg et. al."Application of Fuzzy Logic to Estimate Flow of Methane for Energy Generation at a Sanitary Landfill",Journal of Energy engineering, Vol. 133, No. 4,ASCE,ISSN4-212-223,2007.

[2] Bardossy, A. and Ducksein, L. ,"Analysis of a Karstic Aquifer Management Problem by Fuzzy Composite Programming." Water Resources, Bulletin 28(1),63-73, 1992.

[3] Bellman, R. and L.A.Zadeh, "Decision Making in a Fuzzy Environment." Management Science ,17, pp, 1970, B-144-B-164.

[4] Bender and S.P. Simonovic ,"Fuzzy Compromise Programming “ ,university Manitoba, Winnipeg, MB, Canada, water resources research report no.034, 1996.

[5] Francis Jeffry Pelletier, Review of Met mathematics of fuzzy logics in The Bullet of Symbolic Logic, Vol. 6, No.3, (Sep. 2000), 342-346, JSTOR 421060.

[6] George J. And Bo Yuon, "Fuzzy Sets and Fuzzy Logic Theory and Applications",Prentice Hall of India Private Limited,pp.121-158, 2008.

[7] J.kacprzy and S.H. Nurmi, "Group Decision Making Under Fuzziness" in Fuzzy Sets in Decision Analysis ,operations research and statistics ,R.slowinski ,Ed Norwell ,MA: kluwer , 1998, pp. 103-136.

[8] Lotfi A. Zadeh, "Fuzzy Logic" Stanford Encyclopaedia of Philosophy. Standard University. 2006- 07-23. Retrieved 2008-09-30.

[9] Naim Cagman \& Xiaoting Wang, “A New Group Decision-Making Method Based on Fuzzy Set Operations”,European Journal of Pure and Applied Mathematics, Vol. 4 , No. 1, 2011, 42-49.

[10] Novák, V., Perfilieva, I. and Močkoř, J. "Mathematical principles of fuzzy logic Dodrecht: Kluwer Academic. ISBN 0-7923-8595-0, 1999.

[11] Pathinathan T. And Rajkumar,"Multidimensional Analysis of Poverty Using Fuzzy Set Theory in Rahui Block of Nalanda Distric,Bihar", International Journal of Computing Algorithm, Vol. 03, pp. 704-714,2014. 
[12] Peak,J.H.,Lee, Y.W.and Napier, T.R., "Selection of design/build proposal using fuzzy logic system." Journal of Construction. Engineering and Management, ASCE, 118(2),1992, 303-317.

[13] S. Rajsekaran, G.A., Vijay Lakshmi pai, "Neural Network, Fuzzy Logic and Genetic Algorithm" . Synthesis and Applications, 2004.

[14] S. Salahshour, S. Abbasbandy,T.Allahviranloo,"Ranking Fuzzy Numbers Using Fuzzy Maximizing-Minimizing Points", The author-Published by Atlantis Press,France,2011.

[15] Saaty,T.L.,'The Analytic Hierarchy Process: Planning, Priority Setting,Resource Allocation," McGraw Hill,New-York,1980.

[16] Seo S., Aramaki,T.,Hwang,Y. And Hanaki,K.,'Evaluation of Solid Waste Management System Using Fuzzy Composition”, J. Environ. Eng., 129(6),520-529,2003

[17] Supiah Shamsudin, Azmi Ab Rahman, Zaiton Binti Haron, Lat Da A/P Ai Nam," Water Level Evaluation at Southern Malaysia Reservoir using Fuzzy Composite Programming", International Journal of Engineering and Advanced Technology (IJEAT) ISSN: 2249 -8958 Volume-2, Issue-4, April 2013.

[18] Zadeh, L.A., "Fuzzy sets", Information and Control 8 (3),1965, 338-353.

[19] Zimmermann,"Fuzzy Sets Theory and its Applications", Second, Revised edition, Kluwer Academic Publishers pp.1-21,1996. 